\title{
A percepção materna sobre os sinais neurocomportamentais de bebês pré-termo
} internados na enfermaria pediátrica

\section{The maternal perception of the neurobehavioral signs presented by preterm babies admitted on the inpatient pediatric setting}

\author{
Percepción materna acerca de los señales neurocomportamentales del bebés \\ pretérmino hospitalizados en sala de pediatría
}

\section{Recebido: 05/05/2017 \\ Aprovado: 10/12/2017 \\ Publicado: 30/03/2018}

\author{
Maria Regina Pontes Luz Riccioppo ${ }^{1}$ \\ Lucieny Almohalha²
}

0 estudo teve como objetivo realizar o mapeamento dos sinais neurocomportamentais apresentados por bebês pré-termo a partir do olhar materno. Esta é uma pesquisa descritiva e exploratória, de abordagem qualitativa realizada com 20 mães de bebês pré-termo, através de questionário e checklist do instrumento APIB, no período de outubro de 2011 a janeiro de 2012, em uma enfermaria pediátrica de um Hospital de Clínicas da região do Triângulo Mineiro. Para análise dos dados coletados realizou-se uma descrição simples das frequências absoluta e relativa e utilizou-se o método de análise de conteúdo temática para descrição dos dados qualitativos. Na análise dos sinais apresentados pelos bebês, as mães souberam reconhecer mais os sinais de aproximação do que os de retraimento. Todas as mães disseram observar os seus bebês e relataram a importância do vínculo mãe-filho. Esse fato auxiliou tanto no processo observacional, quanto no fortalecimento do vínculo mãe-bebê, ajudando na criação de estratégias para lidar com a hospitalização.

Descritores: Recém-nascido prematuro; Manifestações neurocomportamentais; Humanização da assistência; Mães.

The aim of the study was to map the neurobehavioral signs presented by preterm infants from the perspective of mothers. This is a descriptive and exploratory qualitative study with 20 mothers of preterm infants carried out through the application of the APIB questionnaire and checklist, from October 2011 to January 2012, in a pediatric ward of a Clinical Hospital in the Triângulo Mineiro region, MG, Brazil. To analyze the data, a simple description of absolute and relative frequencies was performed and the thematic content analysis method was used to describe the qualitative data. In the analysis of the signs presented by the babies, the mothers were able to recognize the signs of approximation more than those of retraction. All mothers reported watching their babies and mentioned the importance of the mother-child bond. This fact helped both in the observational process and in the strengthening of the mother-infant bond, helping to create strategies to deal with hospitalization.

Descriptors: Infant premature; Neurobehavioral manifestations; Humanization of assistance; Mothers.

El estudio tuvo como objetivo realizar el mapeo de las señales neurológicas de comportamiento presentadas por bebés prematuros a través de la mirada materna. Esta es una investigación descriptiva y exploratoria, de abordaje cualitativa realizada con 20 madres de bebés prematuros, a través de cuestionario y check-list del instrumento APIB, en el periodo octubre de 2011 a enero de 2012, en una enfermería pediátrica de un Hospital de Clínicas de la región del Triángulo Minero, Uberaba, MG, Brasil. Para análisis de los datos recolectados se realizó una descripción simple de las frecuencias absoluta y relativa y se utilizó el método de análisis de contenido temático para descripción de los datos cualitativos. En el análisis de las señales presentadas por los bebés, las madres pudieron reconocer más las señales de aproximación que las de retraimiento. Todas las madres dijeron observar a sus bebés y relataron la importancia del vínculo madre-hijo. Ese hecho auxilió tanto en el proceso observacional, como en el fortalecimiento del vínculo madre-bebé, ayudando en la creación de estrategias para lidiar con la hospitalización.

Descriptores: Recién nascido prematuro; Manifestaciones neuroconductuales; Humanización de la atención; Madres.

1 Terapeuta Ocupacional. Especialista em Saúde da Criança e do Adolescente. Mestranda do Programa de Pós-Graduação em Psicologia pela Universidade Federal do Triângulo Mineiro (UFTM), Uberaba, MG, Brasil. ORCID: 0000-0002-8024-8297 E-mail: ma_riccioppo@hotmail.com

2 Terapeuta Ocupacional. Especialista em Saúde Mental. Mestre em Therapeutic Science. Doutoranda em Saúde Pública pela Escola de Enfermagem da Universidade de São Paulo - Ribeirão Preto. Professora do Departamento de Terapia Ocupacional da UFTM, Uberaba, MG, Brasil. ORCID: 0000-0003-0127-1032 E-mail: almohalha@gmail.com 


\section{INTRODUÇÃO}

1 prematuridade é vista como um fator $\triangle$ de risco biológico para o $\triangle$ desenvolvimento infantil, amplia a possibilidade de problemas motores, sensoriais, cognitivos e emocionais e constitui uma situação excepcional para a criança e seus pais e, ainda aumenta fatores de vulnerabilidade, o que exige cuidados redobrados $^{1,2}$. Denomina-se recém-nascido pré-termo (RNPT) o bebê que nasce com idade gestacional inferior a 37 semanas ou 259 dias $^{3}$.

Quando os RNPT estão internados são expostos a ambientes hospitalares ao qual não estão adaptados e que muitas vezes não são compatíveis com sua maturidade neurológica e com a prontidão para emissão de respostas adaptativas aos estímulos advindos do meio ${ }^{4,5}$.

Intervenções repetitivas e dolorosas desencadeiam uma resposta global ao estresse, modificação nos sistemas cardiovascular, respiratório, imunológico, hormonal e comportamental, e interferem no equilíbrio homeostático, promovendo aumento dos gastos energéticos e das necessidades nutricionais. Há estresse excessivo do sistema nervoso central, ainda imaturo do RNPT ${ }^{4,5}$.

Os estímulos em excesso podem gerar processamentos neurológicos pouco congruentes com o nível desenvolvimental do RNPT. Porém, quando a estimulação é oferecida de maneira apropriada, pode-se contribuir com a maturidade neurobiológica, a saúde e o desenvolvimento do bebế.

A longa permanência em cuidados intensivos e estressantes, implica na necessidade de acolhimento os RNPT e seus pais, que vivenciam sentimentos de ansiedade e medo frente à hospitalização dos filhos. Desta forma, é fundamental a humanização do hospital que deve ser receptivo e acolhedor para ambos ${ }^{6,7}$.

A humanização no espaço hospitalar está voltada para o respeito à individualidade, a promoção da segurança do recém-nascido, e ao acolhimento do bebê e de seus pais, por meio do vínculo que a família procura, junto à equipe de saúde. Com o intuito de melhorar a qualidade de vida dos RNPT e de seus pais e fornecer-lhes uma assistência mais humanizada, políticas públicas e modelos teóricos têm sido criados e adotados ${ }^{8}$.

A Abordagem Síncrono-Ativa do Desenvolvimento (synactive), criada por Heidelise Als, preconiza a humanização da assistência ${ }^{9}$. Tal abordagem enfoca que o cérebro do RNPT é um órgão atuante sobre todos os aspectos do seu desenvolvimento, e enfatiza que o funcionamento cerebral do bebê pode ser verificado por meio da observação do seu comportamento.Pode-se assim, demonstrar o limiar do bebê em relação ao estresse, à sua capacidade de autoregulação e do funcionamento de alguns subsistemas, que estão interligados e promovem o equilíbrio ${ }^{10,11}$.

Esta abordagem coloca a necessidade de que profissionais que atuam com bebês e pais desenvolvam habilidades para identificar e interpretar os comportamentos dos RNPT, que podem ser nomeados de sinais neurocomportamentais de aproximação e de retraimento ${ }^{12}$.

Esses sinais irão indicar o nível de organização e desorganização global do corpo do bebê e de seus subsistemas, e se ele necessita de algum auxílio específico. Os sinais neurocomportamentais de aproximação apontam que ele está pronto para receber uma estimulação adequada, demonstrando um equilíbrio homeostático. Já os sinais de retraimento indicam que o bebê está estressado e não está em homeostasia. A importância do reconhecimento desses sinais favorece o desenvolvimento do RNPT ${ }^{11,12}$.

Desde o nascimento, os RNPT estão envolvidos em interações com os adultos e com o ambiente em que vivem. Portanto é primordial receber apoio por parte destes adultos para controlar suas capacidades sociais, interativas e/ou exploradoras ${ }^{13}$.

Desta forma, é essencial que a equipe de saúde saiba sobre esses comportamentos, estimule corretamente a criança, seguindo os sinais neurocomportamentais advindos delae, ensine e oriente os pais quanto a esses sinais ${ }^{7,14}$.

Quando a equipe de saúde e os pais estão integrados nesse processo de intervenção, 
reconhecem e respeitam esses sinais, e consequentemente a maturidade e estabilidade neurofisiológica do RNPT, o cuidado humanizado pode se tornar eficaz.

Nessa direção, o objetivo realizar o mapeamento dos sinais neurocomportamentais apresentados por bebês pré-termo a partir do olhar materno.

\section{MÉTODO}

Trata-se de uma pesquisa descritiva, exploratória de abordagem qualitativa, realizada no período de outubro de 2011 a janeiro de 2012, em uma enfermaria pediátrica de um Hospital de Clínicas da região do Triângulo Mineiro. Participaram do estudo 20 mães de bebês pré-termo hospitalizados na enfermaria destinada exclusivamente para lactentes. A pesquisa foi aprovada pelo Comitê de Ética em Pesquisa da Universidade Federal do Triângulo Mineiro, sob o protocolo de número 1947-11.

Os critérios de inclusão foram: mães que aceitassem participar da pesquisa, que assinassem o Termo de Consentimento Livre e Esclarecido e que tivessem seus bebês nascidos pré-termo com idade cronológica de até 3 meses e internados na enfermaria pediátrica de lactentes por um período mínimo de sete dias. As idades dos bebês e o período de internação foram estipulados respeitando a idade sugerida pelo instrumento de pesquisa, acrescido aí o fato de que sete dias é um período desejável, pois as mães já estabeleceram contato com seus bebês, assim como, uma melhor percepção das respostas comportamentais de seus bebês.

Os dados foram coletados através de um checklist de caráter individual que continha questões:sociodemográficas dos participantes, relacionadas a gestação e ao parto, idade gestacional e, sexo da criança. Ainda neste checklist foi utilizada parte da Avaliação do Comportamento do Bebê Prétermo (ACBP) / Assessment of Preterm Infant Behavior (APIB).

A ACBP/APIB é uma avaliação neurocomportamental que aborda os comportamentos de auto-regulação apresentados pelo bebê pré-termo, à termo e em risco de atrasos no desenvolvimento ${ }^{9,15}$.
Além deste checklist, foi elaborado um roteiro semi-estruturado, contendo perguntas relacionadas às dificuldades encontradas pelas mães para identificação dos sinais neurocomportamentais; sobre o conhecimento delas em relação aos sinais e a importância dada a eles; a valorização da observação e vinculação entre mães e bebês e ainda uma questão, na qual elas poderiam acrescentar qualquer informação extra que julgassem necessário.

Para análise dos dados coletados realizou-se uma descrição numérica simples onde se apresentou as frequências absoluta e relativa de aparição das respostas e utilizouse, para descrição qualitativa, o método de análise de conteúdo temática ${ }^{16}$.

A análise de conteúdo temática consiste em descobrir os núcleos de sentido que compõem uma comunicação, cuja presença ou frequência signifiquem alguma coisa para o objeto analítico visado ${ }^{16}$.

Os dados foram lidos e relidos duas vezes por cada pesquisador em separado e uma vez em grupo e foi realizada a checagem e concordância por ambos das similaridades entre as categorias criadas.

\section{RESULTADOS}

A Tabela 1 mostra o perfil sócio demográfico das mães. Elas residiam em cidades do Triângulo Mineiro. Metade (50\%) tinha idade entre 19 e 30 anos, 35\% possuíam o 2º grau completo, $55 \%$ eram amasiadas e $80 \%$ não trabalhavam fora de casa. A maioria (70\%) eram primíparas e as demais disseram já terem tido filhos prematuros anteriormente.

Em relação ao tipo de parto, 55\% tiveram parto vaginal e $45 \%$ cesário. Com relação às "complicações no parto", a maioria (60\%) não teve nenhuma complicação, porém, das 8 mães (40\%) que disseram ter tido algum tipo de complicação, 7 mencionaram pré-eclâmpsia. 0 pré-natal foi realizado por $90 \%$ das mães.

Para o item "apresentou alguma doença durante a gestação", 9 mães (45\%) disseram que tiveram hipertensão arterial ou problemas de infecção de urina.

Em relação ao quesito "tomou algum medicamento durante a gestação", todas as 
mães disseram "sim", referindo-se à bebês (15\%) nasceram antes de 25 semanas, vitaminas. Sobre o perfil dos 20 bebês, 60\% 10 (50\%) entre 25 e 30 semanas e 7 (35\%) eram do sexo masculino e $40 \%$ feminino. Três entre 31 e 36 semanas.

Tabela 1. Perfil sócio-demográfico das mães dos bebês pré-termo internados em uma enfermaria pediátrica no período outubro de 2011 a janeiro de 2012. Uberaba, 2012.

\begin{tabular}{|c|c|c|}
\hline Perfis & $\begin{array}{l}\text { Número de } \\
\text { mães }\end{array}$ & Respostas (\%) \\
\hline $\begin{array}{l}\text { Idade (em anos) } \\
14 \text { a } 18 \\
19 \text { a } 30 \\
31 \text { a } 40\end{array}$ & $\begin{array}{r}5 \\
10 \\
5\end{array}$ & $\begin{array}{l}25 \\
50 \\
25\end{array}$ \\
\hline $\begin{array}{l}\text { Nível de escolaridade } \\
1^{\circ} \text { incompleto } \\
1^{\circ} \text { completo } \\
2^{\circ} \text { incompleto } \\
2^{\circ} \text { completo } \\
3^{\circ} \text { incompleto } \\
\end{array}$ & $\begin{array}{l}5 \\
5 \\
1 \\
7 \\
2\end{array}$ & $\begin{array}{r}25 \\
25 \\
5 \\
35 \\
10\end{array}$ \\
\hline $\begin{array}{l}\text { Situação Conjugal } \\
\text { Solteiras } \\
\text { Casadas } \\
\text { Amasiadas } \\
\text { Divorciadas } \\
\end{array}$ & $\begin{array}{r}4 \\
4 \\
11 \\
1\end{array}$ & $\begin{array}{r}20 \\
20 \\
55 \\
5\end{array}$ \\
\hline $\begin{array}{l}\text { Trabalham fora } \\
\text { Sim } \\
\text { Não } \\
\end{array}$ & $\begin{array}{r}4 \\
16 \\
\end{array}$ & $\begin{array}{l}20 \\
80 \\
\end{array}$ \\
\hline $\begin{array}{l}\text { Número de filhos } \\
1 \\
2 \\
3 \\
\end{array}$ & $\begin{array}{r}14 \\
3 \\
3 \\
\end{array}$ & $\begin{array}{l}70 \\
15 \\
15 \\
\end{array}$ \\
\hline $\begin{array}{l}\text { Tipo de parto } \\
\text { Normal } \\
\text { Cesário } \\
\end{array}$ & $\begin{array}{r}11 \\
9 \\
\end{array}$ & $\begin{array}{l}55 \\
45 \\
\end{array}$ \\
\hline $\begin{array}{l}\text { Complicações no parto } \\
\text { Sim } \\
\text { Não }\end{array}$ & $\begin{array}{r}8 \\
12 \\
\end{array}$ & $\begin{array}{l}40 \\
60 \\
\end{array}$ \\
\hline $\begin{array}{l}\text { Realização de pré-natal } \\
\text { Sim } \\
\text { Não }\end{array}$ & $\begin{array}{r}18 \\
2\end{array}$ & $\begin{array}{l}90 \\
10\end{array}$ \\
\hline $\begin{array}{llll}\text { Apresentou } & \text { alguma } & \text { doença } & \text { na } \\
\text { gestação? } & & & \\
\text { Sim } & & & \\
\text { Não } & & & \\
\end{array}$ & $\begin{array}{r}9 \\
11\end{array}$ & $\begin{array}{l}45 \\
55\end{array}$ \\
\hline $\begin{array}{l}\text { Tomou algum medicamento durante a } \\
\text { gestação? } \\
\text { Sim } \\
\text { Não }\end{array}$ & $\begin{array}{r}20 \\
0\end{array}$ & $\begin{array}{r}100 \\
0\end{array}$ \\
\hline
\end{tabular}

A Tabela 2 apresenta os resultados relacionados aos sinais neurocomportamentais (aproximação/ retraimento) dos bebês assinalados pelas mães e as respectivas percentagens de respostas.

Observou-se que dentre os 17 sinais de aproximação, 9 (mão à face, aconchegar-se, movimentos corporais, movimentos de preensão, reflexo de procura, sugar, abocanhar, segurar a mão do examinador e, fixar-se visualmente e auditivamente) foram assinalados por mais de $70 \%$ das mães, sendo que 4 deles (movimentos corporais, reflexo de procura, sugar, segurar a mão do examinador) foram assinalados por mais de 90\% delas. Nessa amostra, o sinal de aproximação menos marcado foi o "entrelaçar os dedos", assinalado por somente $25 \%$ das mães.

Dentre os 16 sinais de retraimento, 6 (soluçar, arqueamento de tronco, asa de avião, espirrar, bocejar e, franzir a testa) foram assinalados por mais de $70 \%$ das mães e, destes, 2 (soluçar e bocejar) foram 
assinalados por mais de $90 \%$ das mães, sendo que o sinal de retraimento "bocejar" foi listado por todas elas. 0 sinal de retraimento menos listado foi o "ter náuseas", assinalado por $5 \%$ das mães. Através da análise dos sinais de aproximação/retraimento, notou-se que as mães reconheceram mais os sinais de aproximação do que os de retraimento.

Em relação ao roteiro semiestruturado, de acordo com a pergunta 1"Você encontra dificuldades para identificar estes sinais no seu bebê prematuro?", 2 mães $(10 \%)$ relataram que encontravam dificuldades e 18 (90\%) disseram que não.
Em relação à pergunta 2- "Você tinha conhecimento sobre esses sinais?", 6 mães (30\%) relataram que sim, sendo que 3 dentre essas disseram apenas conhecer os sinais; 1 mãe relatou conhecer os sinais, visto ela observar bastante o seu bebê; outra disse que conhecia apenas os sinais de aproximação e a última mãe disse que já ouviu falar sobre estes em uma palestra, outras 14 mães (70\%) descreveram nunca terem escutado sobre.

Na pergunta 3- "Você acha importante saber sobre esses sinais? Por quê?", todas as mães responderam sim.

Tabela 2. Sinais de retraimento/aproximação assinalados pelas mães de bebês pré-termo internados em uma enfermaria pediátrica no período de outubro de 2011 a janeiro de 2012. Uberaba, 2012.

\begin{tabular}{l|r|l|c}
\hline Sinais de retraimento & \multicolumn{1}{|l}{ \% } & Sinais de aproximação & \% \\
\hline Regurgitar & 20 & Extensão da língua & 55 \\
\hline Ter náuseas & 5 & Mão à face & 80 \\
\hline Soluçar & 90 & Emissão de sons & 50 \\
\hline Movimento peristáltico & 20 & Mãos juntas tocando-se & 55 \\
\hline Caretas, retração de língua & 65 & Pés juntos tocando-se & 50 \\
\hline Arqueamento de Tronco & 85 & Entrelaçar os dedos & 25 \\
\hline Dedos espalhados & 50 & Aconchegar-se & 70 \\
\hline $\begin{array}{l}\text { Asa de avião (abdução de braços } \\
\text { estendidos) }\end{array}$ & 70 & Movimentos corporais & 95 \\
\hline $\begin{array}{l}\text { Saudação (extensão de um ou ambos os } \\
\text { braços) }\end{array}$ & 60 & Mão à boca & 65 \\
\hline Sentando no ar & 60 & Movimentos de preensão & 85 \\
\hline Espirrar & 85 & $\begin{array}{l}\text { Procura de anteparo para os pés } \\
\text { ou pernas }\end{array}$ & 65 \\
\hline Bocejar & 100 & Reflexo de procura & 90 \\
\hline Suspirar & 45 & Sugar & 90 \\
\hline Tossir & 35 & Segurar a mão de examinador & 90 \\
\hline Desviar & 55 & $\begin{array}{l}\text { Fazer 'OHH' com a boca } \\
\text { (arredondando os lábios) }\end{array}$ & 65 \\
\hline Franzir a testa & 80 & $\begin{array}{l}\text { Fixar-se visualmente ou } \\
\text { auditivamente }\end{array}$ & 80 \\
\hline & & $\begin{array}{l}\text { Abocanhar: movimentos de } \\
\text { abertura e fechamento de boca }\end{array}$ & 70 \\
\hline
\end{tabular}

A Tabela 3 traz o relato das mães referente ao "por que elas acham importante saber sobre os sinais de retraimento e aproximação". Na pergunta 4- "Você observa muito seu bebê?", e 5- "Você acha importante ter um vínculo com seu filho? Por quê?" todas as mães responderam sim. A Tabela 3 também apresenta o relato das mães sobre a importância do vínculo.

A última pergunta do roteiro não foi respondida por nenhuma mãe. De acordo com as respostas das mães, referentes às perguntas 3 e 5 do roteiro, todas as mães responderam e na pergunta 5 somente 2 mães $(10 \%)$ não souberam dar uma resposta. 
Tabela 3. Importância de vínculo de acordo às mães de bebês pré-termo internados em enfermaria pediátrica. Uberaba 2012.

\begin{tabular}{|c|c|c|c|}
\hline Mães & Idade & $\begin{array}{l}\text { Por que você acha importante reconhecer } \\
\text { os sinais apresentados pelo bebê? }\end{array}$ & $\begin{array}{l}\text { Por que você acha importante ter um vínculo com seu } \\
\text { bebê? }\end{array}$ \\
\hline 1 & 38 & Para ficar por dentro e saber mais sobre & Não respondeu \\
\hline 2 & 23 & Para saber se o filho está bem & $\begin{array}{l}\text { Para desenvolver mais rápido, principalmente quando } \\
\text { conhece a mãe }\end{array}$ \\
\hline 3 & 29 & Para conhecer bem o filho & $\begin{array}{l}\text { É essencial, pois ficar junto com ele faz toda a diferença } \\
\text { para sua recuperação }\end{array}$ \\
\hline 4 & 25 & Para ver se o filho está desenvolvendo bem & Não soube explicar \\
\hline 5 & 40 & Para conhecer o bebê & $\begin{array}{l}\text { Porque se conhece melhor o bebê e passa a descobrir } \\
\text { muita coisa }\end{array}$ \\
\hline 6 & 16 & $\begin{array}{l}\text { Porque a mãe está a todo momento perto do } \\
\text { seu filho }\end{array}$ & Porque causa um amor grande \\
\hline 7 & 37 & $\begin{array}{l}\text { Para prestar atenção e aprender a lidar com } \\
\text { ele }\end{array}$ & Porque ele é meu filho \\
\hline 8 & 25 & $\begin{array}{l}\text { Para ter noção de entendimento, pois o bebê } \\
\text { não fala }\end{array}$ & $\begin{array}{l}\text { Para dar atenção, amor, carinho, entendê-lo; pois ele não } \\
\text { fala, então dá sinais para eu entender }\end{array}$ \\
\hline 9 & 24 & Porque a informação ajuda em tudo & Porque é essencial ter esse vínculo \\
\hline 10 & 16 & $\begin{array}{l}\text { Porque é bom, pra evitar os problemas, } \\
\text { doenças. Quanto mais saber, melhor }\end{array}$ & $\begin{array}{l}\text { Gosto de observar porque tem horas que de olho fechado } \\
\text { ela ri para a gente }\end{array}$ \\
\hline 11 & 36 & Para acompanhar direito o tempo todo o bebê & Para observar o que está se passando, se está tudo bem \\
\hline 12 & 22 & $\begin{array}{l}\text { É um meio de entender eles, e eles entender a } \\
\text { gente }\end{array}$ & $\begin{array}{l}\text { Na amamentação principalmente, porque ficarmos } \\
\text { unidos é um jeito de se comunicar }\end{array}$ \\
\hline 13 & 14 & $\begin{array}{l}\text { Para saber a hora que ele está gostando e o } \\
\text { que a gente faz com ele }\end{array}$ & Porque futuramente vai ser muito apegado um ao outro \\
\hline 14 & 17 & $\begin{array}{l}\text { Para saber quando ela está gostando ou não, } \\
\text { para poder fazer o que ela gosta }\end{array}$ & $\begin{array}{l}\text { É importante ficar reparando porque eles crescem e você } \\
\text { nem vê depois }\end{array}$ \\
\hline 15 & 22 & $\begin{array}{l}\text { Porque sabendo é mais fácil de lidar com as } \\
\text { coisas }\end{array}$ & $\begin{array}{l}\text { Ele é novo, na hora de mamar é um vínculo sem } \\
\text { explicação }\end{array}$ \\
\hline 16 & 14 & Para saber quando eles querem alguma coisa & Para o bebê ficar próximo da mãe e mais calmo \\
\hline 17 & 28 & $\begin{array}{l}\text { O sinal de retraimento eu não conhecia. É } \\
\text { importante saber por que é um sinal que não } \\
\text { está bem, aí como ele não vai falar, ele vai } \\
\text { mostrar }\end{array}$ & $\begin{array}{l}\text { É essencial, porque nesse mundo agora, na vida dele, ele } \\
\text { só conhece a mim né, que sou mãe }\end{array}$ \\
\hline 18 & 20 & Porque a gente aprende & $\begin{array}{l}\text { Porque você sente mais aproximação da sua filha, } \\
\text { carinho. Ela depende disso }\end{array}$ \\
\hline 19 & 32 & $\begin{array}{l}\text { Porque às vezes, a criança precisa de algum } \\
\text { cuidado maior e você não sabe identificar }\end{array}$ & $\begin{array}{l}\text { Porque por ela ser prematura, a mãe não teve contato } \\
\text { com ela e depois desses } 15 \text { dias o bebê melhorou } \\
\text { bastante e está menos estressada }\end{array}$ \\
\hline 20 & 24 & Para saber né & $\begin{array}{l}\text { É bonito conversar com ela, parece que ela entende o que } \\
\text { eu falo }\end{array}$ \\
\hline
\end{tabular}


No tocante as falas das mães pesquisadas três categorias foram evidenciadas:

a) Reconhecendo os sinais apresentados por meu bebê;

b) Meu filho e seu desenvolvimento; e,

c) Importância do processo de comunicação entre mãe e filho.

\section{DISCUSSÃo}

A assistência ao RNPT e a seus pais tornou-se mais humanizada. Os pais que convivem com seus bebês internados sentem-se realizados por auxiliar e participar na recuperação do filho ${ }^{17}$.

Acredita-se que, quanto mais a assistência for humanizada, melhor para os pais e para o estado de saúde do bebê. Se um bebê prematuro é tocado, acariciado, ou se alguém conversar com ele durante sua estadia na enfermaria é provável que ele ganhe peso, apresente menos pausas respiratórias e um progresso em áreas de maior complexidade de funcionamento cerebral ${ }^{18}$.

Essa questão pôde ser observada na fala de uma das mães, que utilizou a comunicação como uma estratégia humanizada para auxiliar no desenvolvimento de seu bebê:

É bonito conversar com ela, parece que ela entende o que eu falo.(mãe 20)

Na humanização da assistência, as mães passaram a ser consideradas aliadas e a terem um papel fundamental no cuidado do filho ${ }^{19,20}$. A permanência materna durante a hospitalização tornou-se algo fundamental para essa nova forma assistencial e para o processo de vinculação afetiva entre mãe e bebê prematuro.

As falas das mães participantes demonstraram tais experiências vividas e preconizadas pelas políticas públicas atuais: $\hat{E}$ essencial, pois ficar junto com ele faz toda a diferença para sua recuperação.(mãe 3).

É essencial, porque nesse mundo agora, na vida dele, ele só conhece a mim né, que sou mãe.(mãe17)

Tendo a oportunidade de ficar com seu filho no hospital e passar um tempo realizando o papel maternal implicará positivamente no processo de conhecimento do filho, dos sinais comportamentais apresentados por ele e em especial no desenvolvimento da criança.

Na categoria intitulada "Reconhecendo os sinais apresentados por meu bebê", em relação à pergunta "Por que você acha importante reconhecer os sinais apresentados pelo bebê?", a maioria das mães relatou não haver dificuldade em observar os sinais apresentados por seus filhos e que achavam importante saber sobre estes.

Isso favoreceu questionar se, devido ao fato de passarem a maior parte do tempo com seus bebês na enfermaria, elas adotaram essa conduta de cuidado ou se a equipe as orientou quanto à forma de cuidado adequado para com os bebês, ou ainda, a preocupação com a prematuridade e à necessidade de assistência diferenciada.

Em um dos relatos, uma mãe ressaltou que, após um maior contato com seu bebê, ela pôde notar o seu progresso, o que a fez pensar que esse contato foi realmente essencial para o desenvolvimento dele:

Porque por ela ser prematura, a mãe não teve contato com ela antes e depois desses 15 dias o bebê melhorou bastante e está menos estressada.(mãe 19)

É importante buscar os gestos dos RNPT para que se possa oferecer cuidados de saúde que levem em consideração o bebê como sujeito $^{20}$. E foi isso que se observou nos seguintes relatos das mães:

Porque é bom, pra evitar os problemas, doenças. Quanto mais saber, melhor. (mãe 10)

Pra saber a hora que ele está gostando e o que a gente faz com ele. (mãe 13)

Pra saber quando eles querem alguma coisa.(mãe ${ }_{16}$ )

Porque às vezes, a criança precisa de algum cuidado maior e você não sabe identificar. (mãe 19)

$\mathrm{O}$ fato de as mães ficarem preocupadas e estarem atentas com os seus bebês foi de encontro com a teoria da preocupação materna primária, que consta de um estado de muita sensibilidade, onde a mãe tem uma preocupação com seu bebê e busca atender às suas necessidades ${ }^{21}$. Nesta pesquisa as mães demonstraram preocupação e curiosidade em relação aos sinais apresentados pelos bebês, 0 que as sensibilizou para maior acolhimento ao filho.

Os relatos das mães sobre a importância da identificação dos sinais neurocomportamentais e sobre a pergunta: "Por que você acha importante ter um vínculo 
com seu bebê?", levaram à criação da categoria temática, "Meu filho e seu desenvolvimento", onde se destacaram os seguintes relatos:

Para conhecer bem o filho.(mãe 3)

Para ver se o filho está desenvolvendo bem. (mãe 4)

Porque se conhece melhor o bebê e passa a descobrir muita coisa. (mãe 5)

Pra prestar atenção e aprender a lidar com ele .(mãe 7) Pra observar o que está se passando, se está tudo bem.(mãe 11)

Muitas vezes, o bebê poderá ter um sofrimento de longo prazo e isso acarretará em riscos desenvolvimentais, que podem influenciar na interação com os pais e serem prejudiciais no desenvolvimento psíquico. Desta forma, é essencial que a mãe do RNPT compreenda as capacidades e as fraquezas de seu filho, auxiliando assim a intervir no momento de organização dos sistemas fisiológicos ${ }^{11}$.

A vivência com o RNPT pode ser considerada importante, pois através do contato precoce é possível observar quando o bebê começou a se recuperar e quando utilizou uma melhor comunicação ${ }^{20}$. Com isso, o tempo de permanência da mãe com seu bebê influenciou no reconhecimento dos sinais apresentados por ele e no processo de vinculação.

Na categoria "Importância do processo de comunicação entre mãe e filho", a maioria das falas trouxe a essência desta relação como um momento único e enriquecedor do vínculo entre ambos:

Pra dar atenção, amor, carinho, entendê-lo; pois ele não fala, então dá sinais para eu entender .(mãe 8)

0 vínculo afetivo, que consiste na aproximação e interação o mais precoce possível entre mãe e filho desenvolve-se constantemente e tem o papel de trazer proteção e sobrevivência ao bebê; promover comunicação com seus pais, e assim o seu desenvolvimento normal é principiado ${ }^{20,22}$.

A Teoria do Vínculo preconizada por Henrique Pichon-Riviére, propõe que todo sistema familiar, considerado um grupo de relações sociais, são caracterizadas por papeis e funções, onde cada membro se complementa promovendo assim o sentimento de pertencimento que influencia o funcionamento do grupo ${ }^{27}$.
O vínculo faz parte da vida das pessoas, promove laços de família e qualidade nas relações estabelecidas nos primeiros anos de vida. Sendo portanto, um fator determinante no processo de desenvolvimento cognitivo e emocional.

A manutenção do vínculo durante a hospitalização é importante também para os cuidadores do bebê, pois os auxilia no incentivo do oferecimento de oportunidades e suporte para o cuidado do bebê e para aumentar seu processo de recuperação. Esse apego entre mãe-filho tem significado para o desenvolvimento e bem-estar de ambos ${ }^{23,24}$.

Quando a mãe e o bebê interagem, iniciase uma série de eventos sensoriais, hormonais, fisiológicos, imunológicos e comportamentais, os quais contribuem positivamente para o vínculo e que vão de acordo com a abordagem síncrono-ativa ${ }^{7,11}$.

A comunicação entre mãe e bebê, mesmo que silenciosa, é sensível aos sinais um do outro e é capaz de proteger o bebê de reações automáticas a fatores intrusos do meio. Para tanto, é importante que as mães tenham percepções sutis em relação aos comportamentos de seus bebês. Isso também ajudará as mães na percepção de quanto exatamente manipular o bebê ou deixá-lo sossegado e pode se tornar um mecanismo de enfrentamento do estresse vivido no processo de hospitalização ${ }^{25}$.

É importante também uma rede de apoio para os pais advinda da equipe de saúde durante o processo de hospitalização. Essa rede poderá auxiliar e garantir um ambiente saudável para o bebê e acolhedor para sua mãe e familiares ${ }^{20,26}$. Isso não foi apontado nas falas das mães, o que se faz indagar se elas tinham conhecimento do quão importante é a intervenção da equipe com a família, para o auxílio no desenvolvimento global do RNPT e para a facilitação da vivência hospitalar.

0 reconhecimento dos sinais neurocomportamentais é fundamental para que se identifique o que o bebê está sentindo, quando está bem ou quando está vivenciando estresse. É importante que os pais estejam engajados no processo de internação, pois é nesse momento que eles estão susceptíveis a 
fortes emoções, conflitos e sentimentos que envolvem os familiares, o bebê e a equipe.

Para tal, uma capacitação de todos que adentram nesse contexto hospitalar, sejam os profissionais de saúde ou as famílias, deve acontecer. Além disso, deve ser preconizada a assistência de excelência ao bebê e à sua mãe além de ser valorizado o seu papel materno nos cuidados ao bebê.

\section{CONCLUSÃO}

Observou-se neste estudo que as mães de bebês pré-termo conseguiram visualizar mais os sinais neurocomportamentais de aproximação do que os de retraimento apresentados pelos bebês.

0 fato das mães terem um processo de vinculação afetiva com seus bebês durante o processo de internação auxiliou na observação dos sinais apresentados por eles e na criação de estratégias para lidar com a hospitalização.

Ficou evidente que mais do que observar o bebê, cabe a importância de um processo de escuta ativa e de capacitação dessas mães e de toda a equipe.

Devido à poucas referências sobre o assunto abordado, espera-se que esta pesquisa possa contribuir para a promoção de uma assistência mais humanizada na área da saúde e, possa gerar novas hipóteses para futuras pesquisas que também abordem tal temática e ainda garantam um atendimento voltado às necessidades neurodesenvolvimentais de bebês, que se inclua os pais de forma ativa no processo de integralidade dos cuidados.

\section{REFERÊNCIAS}

1. Marchetti D, Moreira, MC. Vivências da prematuridade: a aceitação do filho real pressupõe a desconstrução do bebê imaginário? Rev Psicol Saúde. 2015; 7(1):82-9.

2. Reis ACH. Prematuridade e desenvolvimento: caracterização do perfil desenvolvimental de um grupo de crianças prematuras. [dissertação] Porto: Universidade Católica Portuguesa, Faculdade de Educação e Psicologia; 2013. 51p.

3. Ministério da Saúde (Br). Secretaria de Atenção à Saúde, Departamento de Ações Programáticas Estratégicas. Manual técnico: pré-natal e puerpério: atenção qualificada e humanizada.
Brasília, DF: Ministério da Saúde; 2006. 162 p. (Série A. Normas e Manuais Técnicos, Série Direitos Sexuais e Direitos Reprodutivos, Caderno n. 5).

4. Silva PC, Marinho EFC, Santos LOS. A percepção dos profissionais de saúde sobre a dor em prematuros. Diálogos Ciênc. 2016; 16(36):39-51.

5. Gorźlio DM. Desenvolvimento neurocomportamental em neonatos pré-termo hospitalizados relacionados com indicadores de estresse e dor. [dissertação]. Ribeirão Preto (SP): Faculdade de Filosofia, Ciências e Letras de Ribeirão Preto, Universidade de São Paulo; $2013.129 \mathrm{f}$.

6. Cypel S. Humanização do atendimento ao recém-nascido: a importância das relações interpessoais e a organização neurobiológica. Einstein. 2007; 5(1):69-73.

7. Ministério da Saúde (Br), Secretaria de Atenção à Saúde, Núcleo Técnico da Política Nacional de Humanização. HumanizaSUS: documento base para gestores e trabalhadores do SUS. 4 ed. Brasília, DF: Ministério da Saúde; 2010. 72 p. (Série B. Textos Básicos de Saúde).

8. Roseiro CP, Paula KMP. Concepções de humanização de profissionais em Unidades de terapia intensiva neonatal. Estud psicol. 2015; 32(1):109-19.

9. Als H, Lester BM, Tronick E, Brazelton TB. Towards a research instrument for the assessment of preterm infants' behavior (APIB) and manual for the assessment of preterm infants' behavior (APIB). In: Fitzgerald HE, Lester BM, Yogman MW. Theory and research in behavior pediatrics. New York: Plenum Press, 1982.

10. Ottoni ACS, Grave MTQ. Avaliação dos sinais neurocomportamentais de bebês pré-termo internados em Unidade de Terapia Intensiva Neonatal. Rev Ter Ocup. 2014; 25(2):151-8.

11. Meyerhof PG. O neonato de risco - propostas de intervenção no ambiente e no desenvolvimento. In: KUDO AM., organizadores. Fisioterapia, fonoaudiologia e terapia ocupacional em pediatria. São Paulo: Sarvier. 1997. p. 204-222.

12. Als H. Newborn individualized developmental care and assessment program (NIDCAP): new frontier for neonatal and perinatal medicine. J Neonatal-Perinat Med. 2009; 2:135-47.

13. Holloway E. Como favorecer o entretenimento progenitor-lactente na Unidade de Terapia Intensiva Neonatal. In: Parham LD, Fazio LS. A recreação na terapia ocupacional pediátrica. São Paulo: Livraria Santos; 2012. p. 171-183.

14. Almohalha L, Guerra RMR. Identificação dos sinais neurocomportamentais de bebês pré-termo por profissionais que atuam na Unidade de 
Terapia Intensiva Neonatal (UTIN). Rev Ter Ocup. 2011; 22(2):117-26.

15. Kudo AM, Marcondes E, Lins L, Moriyama LT, Guimarães ML, Juliana RC, et al. Fisioterapia, fonoaudiologia e terapia ocupacional em pediatria. 2ed. São Paulo: Sarvier; 1997.

16. Minayo MCS. Pesquisa social: teoria, método e criatividade. 31ed. Petrópolis: Vozes; 2012.

17. Frigo J, Zocce DAA, Palavro GL, Turatti LA, Neves ET, Schaefer TM. Percepções de pais de recém-nascidos prematuros em unidade de terapia intensiva neonatal. Rev Enferm UFSM. 2015; 5(1):58-68.

18. Klaus MH, Kennel JH, Klaus PH. Vínculo: construindo as bases para um apego seguro e para a independência. Porto Alegre: Artes Médicas; 2000.

19. Spehar MC, Seidl LMF. Percepções maternas no método canguru: contato pele a pele, amamentação e autoeficácia. Psicol Estud. 2013; 18(4):647-56.

20. Ministério da Saúde (Br). Secretaria de Atenção à Saúde. Departamento de Ações Programáticas Estratégicas. Atenção humanizada ao recém-nascido de baixo peso: método canguru. 2ed. Brasília, DF: Ministério da Saúde; 2013. 204 p. (Série A. Normas e Manuais Técnicos).

21. Winnicott D. Da pediatria à psicanálise: obras escolhidas. Rio de Janeiro: Imago; 2000.

22. Roso CC, Costenaro RGS, Rangel RF, Jacobi CS, Mistura C, Silva CT et al. Vivências de mães sobre a hospitalização do filho prematuro. Rev Enferm UFSM. 2014; 4(1):47-54.

23. Araújo BBM, Rodrigues BMRD, Pacheco STA. A promoção do cuidado materno ao neonato prematuro: a perspectiva da educação problematizadora em saúde. Rev enferm UERJ. 2015; 23(1):128-31.

24. Marciano RP. A constituição do vínculo materno com o bebê prematuro: possibilidades de intervenção precoce. [dissertação]. Goiânia: Universidade Federal de Goiás; 2016. 142p.

25. Toledo S. Diálogo tônico: a silenciosa comunicação mãe-bebê. Cad Psicanal (Círc. Psicanal. Rio J.). 2009; 31(22):193-205.

26. Joaquim RHVT, Silvestrini MS, Marini, BPR. Grupo de mães de bebês prematuros hospitalizados: experiência de intervenção de Terapia Ocupacional no contexto hospitalar. Cad Ter Ocup UFSCar. 2014; 22(1):145-50.

27. Pichon-Riviére H. Teoria do vínculo. 3ed. São Paulo: Martins Fontes; 1988.

CONTRIBUIÇÕES
Maria Regina Pontes Luz Riccioppo atuou
na concepção e redação do artigo, análise e
interpretação dos dados. Lucieny
Almohalha participou na concepção e
redação do artigo; delineamento, análise e
interpretação dos dados e, revisão crítica.

\footnotetext{
Como citar este artigo (Vancouver)

Riccioppo MRPL, Almohalha L. A percepção materna sobre os sinais neurocomportamentais de bebês pré-termo internados na enfermaria pediátrica. REFACS [Internet]. 2018 [citado em inserir dia, mês e ano de acesso];6(X):XXX-XXX. Disponível em: inserir link de acesso. DOI: inserir link do DOI.

\section{Como citar este artigo (ABNT)}

RICCIOPPO, M. R. P. L.; ALMOHALHA, A. A percepção materna sobre os sinais neurocomportamentais de bebês pré-termo internados na enfermaria pediátrica. REFACS, Uberaba, v. 6, n. X, p. XX-XX, 2018. Disponível em: <inserir link de acesso >. Acesso em: inserir dia, mês e ano de acesso. DOI: inserir link do DOI.

\section{Como citar este artigo (APA)}

Riccioppo, M. R. P. L. \& Almohalha, L.(2018). A percepção materna sobre os sinais neurocomportamentais de bebês pré-termo internados na enfermaria pediátrica. REFACS, 6(X), XXXX. Recuperado em: inserir dia, mês e ano de acesso de inserir link de acesso. DOI: inserir link do DOI.
} 